\title{
Novel Coronavirus (COVID-19) in India
}

\author{
Noble K Kurian* \\ RNB Global University, Bikaner, Rajasthan, INDIA \\ *Corresponding email: noble.kurian@ rnbglobal.edu.in
}

\begin{abstract}
Novel Coronavirus infection mediated pandemic started in China in December 2019 and is still killing 1000s of people throughout the world. The second most populous country, India too is fighting against this infectious disease. The country is taking effective measures to curb the pandemic by exerting extensive campaigning on sanitation and strict social distancing measures to quell the explosion of the infection rate. The future of the COVID-19 infections in India still remain unpredictable, so precautionary methods need to be continued until the growth rate of new cases drop below one.
\end{abstract}

Keywords: COVID-19, Corona virus, India

Human coronaviruses were first identified in the 1960s and interest in these viruses advanced significantly in 2002 from the emergence of Severe Acute Respiratory syndrome CoV (SARS$\mathrm{CoV}$ ) which killed 774 people around the world with a mortality rate of 9.5\% (Drosten et al. 2003; Ksiazek et al. 2003; Peiris et al. 2003). This virus can infect even dogs (fake news are spreading that it can't infect dogs) as well as cats (Fehr and Perlman. 2015; Kahn and McIntosh. 2005) that are domesticated. Later it spread to the Middle East region as the Middle East Respiratory Syndrome CoV (MERS-CoV) (Zaki et al. 2012) that killed 919 people with a very high mortality rate of 35\%. In December 2019, it has reappeared in Wuhan, China and has spread to 199 countries killing 21031 people (World Health Organization 2020) to date and has been declared a pandemic by the World Health Organization. The Wuhan CoV viral genome sequencing shows less similarity with the earlier reported CoVs suggesting a novel CoV strain (2019-nCoV), that has now been termed as Severe acute respiratory syndrome CoV-2 (SARS-CoV-2) or COVID-19. $2019-\mathrm{nCoV}$ is thought to reach humans through animals especially bats and the exact mode of transmission still remain unknown (Dhama et al. 2020). The mortality rate of this novel virus falls between 1-3\% (Novel, C. P. E. R. E. 2020) and its transmission competence is very high compared to its earlier counterparts as it kills more people than the earlier efficient killer CoV strains.

2019-nCoV is a single-stranded RNA virus that initially invades the lung parenchyma and causes severe interstitial inflammation of the lungs. The infected individuals often have alveolar damage that could lead to acute respiratory distress syndrome. The patient often suffers from lymphocytopenia which often correlates with the severity of the disease. Acute respiratory distress syndrome can result in cytokine storm and non-regulatory immune responses may eventually lead to multiple organ failures. Most cases of 2019-nCoV infections are associated with pneumonia and injury in hepatic tissues (Dhama et al. 2020). 
Currently, Italy is worst affected with 75000 people infected of which 7700 died accounting to roughly about $10.2 \%$ mortality rate. The whole of Europe especially Spain and Germany are infected drastically. In the United States of America also infection is widespread but the mortality rate is about 1.3\%. Middle Eastern countries have also been hit and Iran has reported over 32000 COVID-19 patients and more than 2000 deaths. Africa has so far has not been much affected by COVID-19 infection with Egypt and Algeria reporting 21 and 17 deaths respectively. In the Indian subcontinent COVID-19 is still escalating, apart from India, 8 and 5 deaths were reported in Pakistan and Bangladesh respectively (World Health Organization 2020).

\section{How it came to India?}

In India, the first 2019-nCoV infection case was reported on January 30, 2020, according to the Ministry of Health and Family Welfare, Government of India. Many of the initial cases in India came from contact with the people having a history of traveling from Iran, Italy, and China. The first case was three persons travelled from Wuhan, China to Kerala, India which is now considered as the epicenter of the pandemic. Later throughout India, the people who met travelers from infected countries contracted with the disease. First COVID-19 death in the country was reported on March $13^{\text {th }}, 2020$ (MOHFW, India). Although being a country of 1.2 billion and a neighbor of China, India has fairly contained the spread of COVID-19 infection to date.

\section{Current situation}

Though the COVID-19 cases were being tested and identified in India from February but late development of symptoms has caused a rapid spread of infection and consequently, implementation of immediate quarantine measures after the first week of March, 2020 when the first person succumbed to the disease. The country has seen a steep rise (Fig. 1) in the number of confirmed positive patients on $19^{\text {th }}$ and $21^{\text {st }}$ March with a high infection growth rate of 4.66 and 3.69 respectively (Fig. 2). The country is now in the exponential phase of COVID-19 infection and showing great nonlinearity in the new cases reported daily. A growth factor value between 0 and 1 (Fig.2) is an indication of a decline in infection, but the growth factor following lockdown in the country had gone down to 0.476 ( $26^{\text {th }}$ March, 2020), which on the very next day ( $27^{\text {th }}$ March, 2020) raised to 2.1 (Fig. 2). This shows the unpredictability of cases being reported in the country (MOHFW, India). 


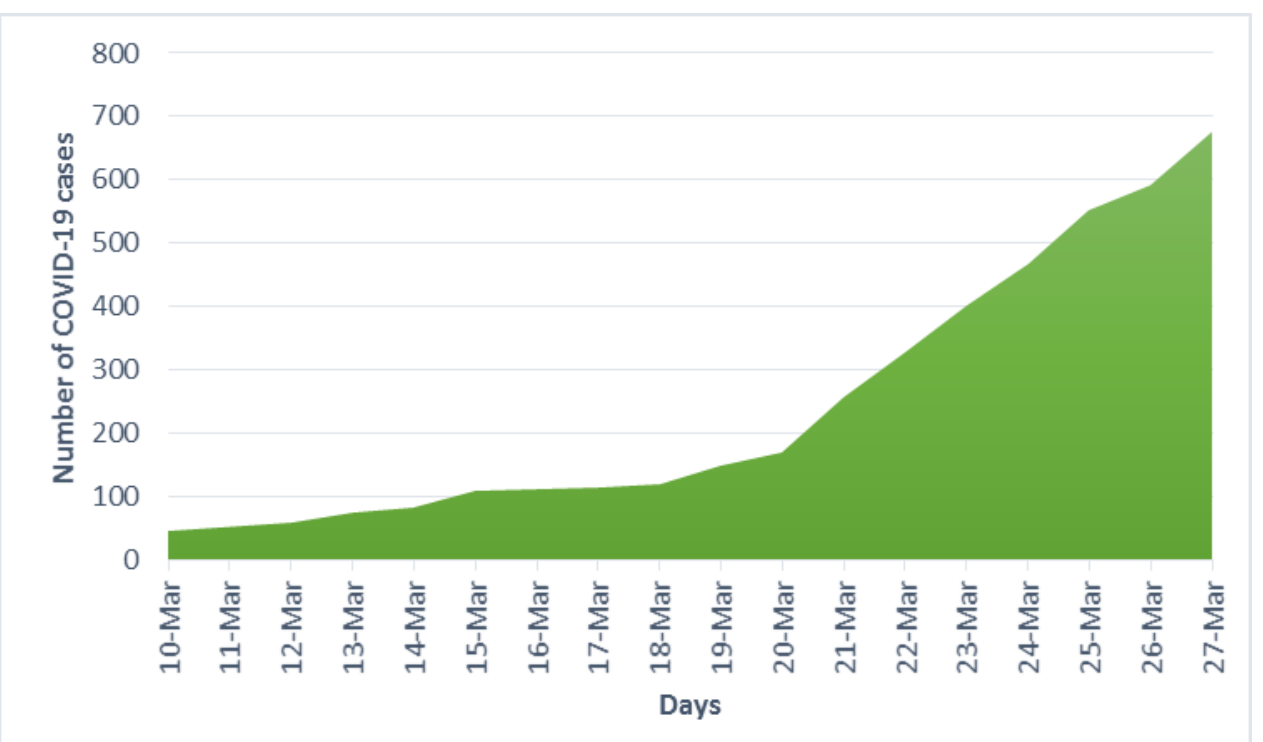

Figure 1: Number of COVID-19 patients in India till March 27, 2020 (Source: mohfw.gov.in)

On carefully analyzing the growth factor chart of COVID-19 (Fig.2) cases also reveal the unpredictability of infection in India. On $15^{\text {th }}$ March the growth factor steeped up to 2.88 and after four days on $19^{\text {th }}$ March it again raised to 4.66 and on $21^{\text {st }}$ to 3.69 then after six days on $27^{\text {th }}$ to 2.1 . This nonlinearity reports may be due to inadequate or random screening which may miss many number of infected individuals remain unchecked.

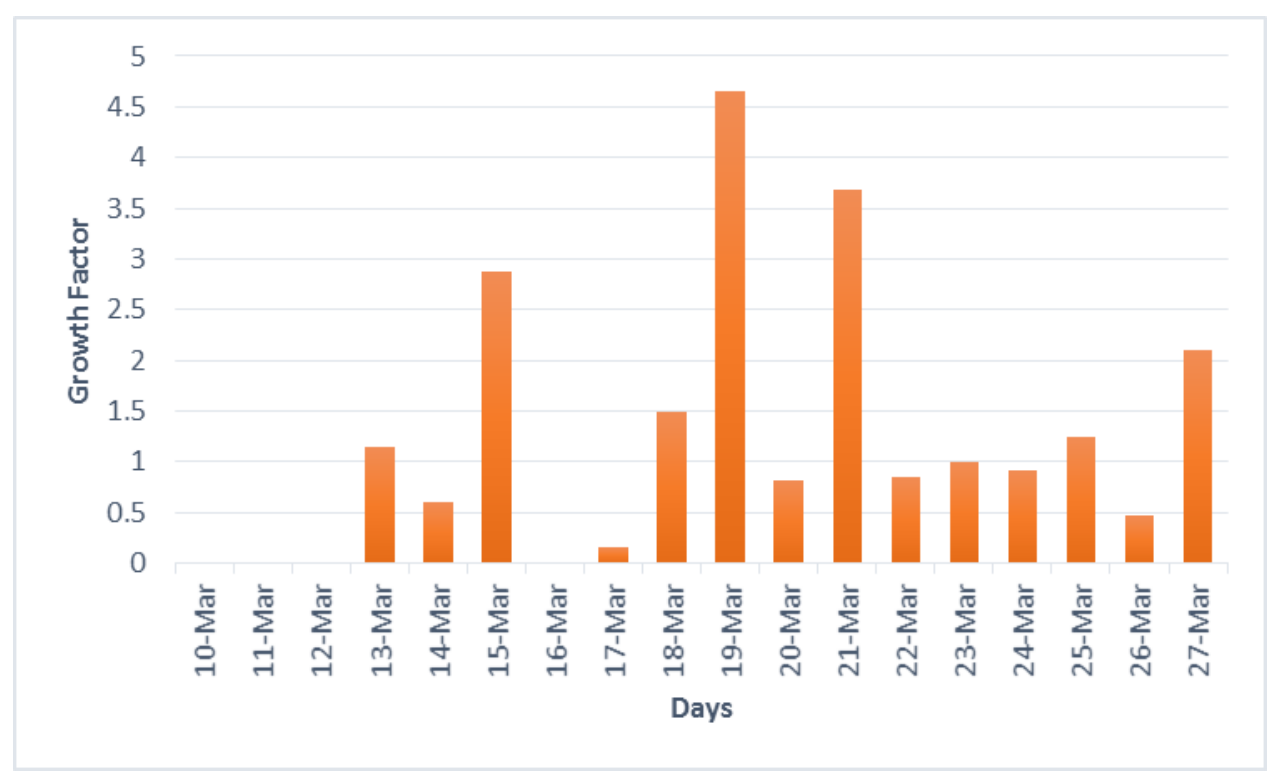

Figure 2: Growth factor of COVID-19 cases in India (Growth factor is calculated by dividing the new cases in the present day to the new cases in the previous day)

The figures show fluctuations in the number of infected new cases in the country but the correlation between the recovered cases and total deaths look alarming. As only 9.89\% (Fig.3) of the infected individuals have recovered to date and the total death about $2.5 \%$ (which is close to the rate of 
mortality in China), the chances of community transmission of the disease is more as the country is highly populous with less availability of medical facilities to accommodate the infected individuals if the number goes high (MOHFW, India).

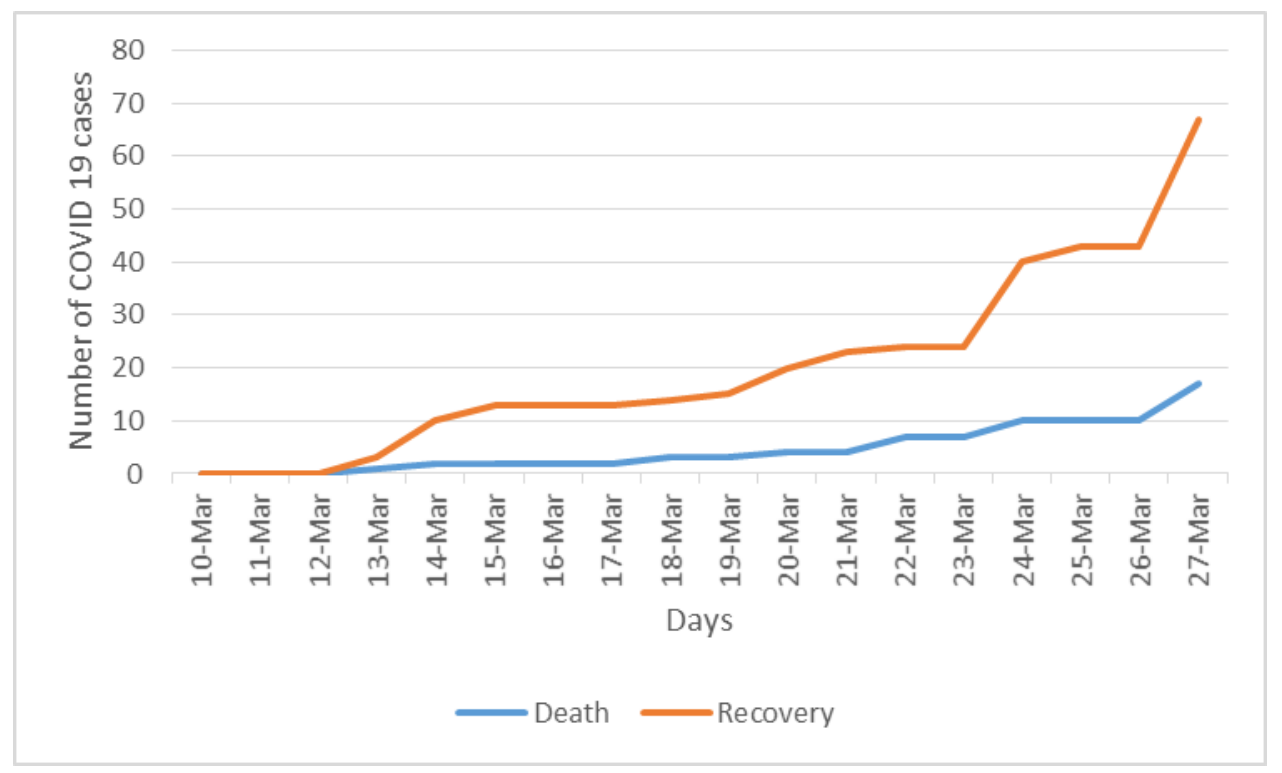

Figure 3: Death vs. Recovery of COVID19 cases in India

\section{Lockdown?}

As the growth rate of COVID-19 infections rose up on $21^{\text {st }}$ March 2020, the prime minister of India Shri. Narendra Modi declared a so-called one-day lockdown on $22^{\text {nd }}$ March 2020 in name 'Janata Curfew' which lowered the growth rate of cases from 3.69 to 1 (Fig.2; Fig. 4). (MOHFW, India). This resulted in the declaration of a 21 day long further lockdown in the country to $14^{\text {th }}$ April 2020. On the fifth day of the lockdown again a rise in growth rate of infected individuals was observed. This raised the question of whether the lockdown is effective or not.

Being a country of 100 million people the effectiveness of imparting lockdown is a major hurdle to the Government. A minor percentage of people still behave slack and impetuous about the lockdown have become super-spreaders of their community. Even $0.1 \%$ of ignorant people of the country are a huge population that can spread the pandemic vigorously. Another reason for an up rise in new cases during the lockdown period may be due to inefficient screening practices. Scarcity of volunteers, unavailability of screening kits, improper voluntary reporting of patients may also be some of the main causes of inefficient screening and skewed statistics. But the lockdown has considerably slowed down the infection rate compared to other countries which will be discussed further. 


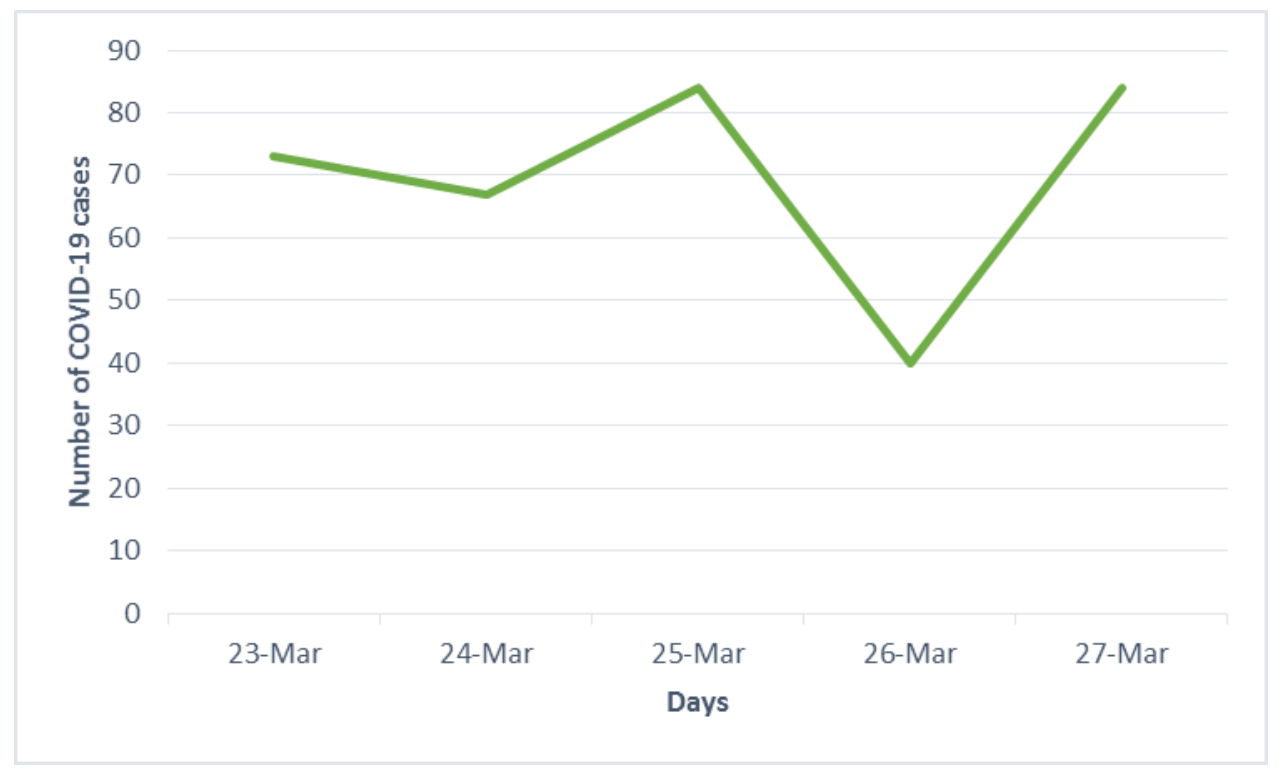

Figure 4: Number of new cases during the lockdown period

\section{India vs. China}

According to the World Health Organization in China where the infection first started is in the declining phase of the pandemic while countries like Italy, the US, Iran, Spain, and India are in the exponential phase. In China the infection spread began uncontrollably by January end later had an exponential rise during the mid of February. In Figure 5 we can see a steep rise in the number of cases between February 14 and 17. Considerable decline in the number of infected cases started around the second week of March 2020 (World Health Organization 2020).

Following this pattern of infection observed in China, it is evident that the number of cases in India is comparatively less. In India (Fig. 5) the number of cases is increasing exponentially but not as vigorously as seen in China. Lockdown in India has controlled the number of infections and still a chance of a steep increase before the fall can't be ruled out. Further following lockdown and social distancing throughout the government instructed 21 days can decrease the pandemic without further uprise (MOHFW, India). 


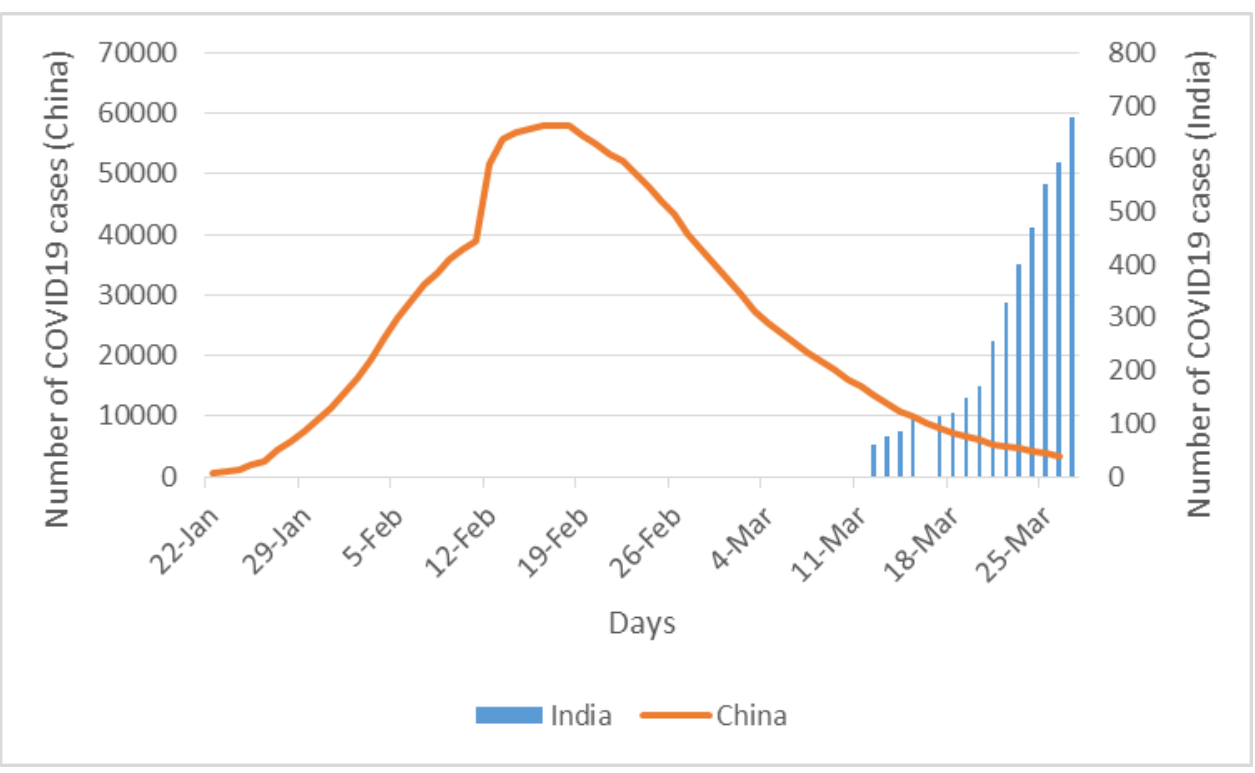

Figure 5: COVID 19 disease progression pattern in India and China (Source: who.int)

\section{Controlling the pandemic?}

Development of a vaccine against 2019-nCoV will take lot of time due to its extensive diverse antigenic variants (Graham et al. 2013). Hence, vaccines against SARS and MERS have not yet been successfully developed (Malik et al. 2020). Two drugs, remdesivir (GS-5734) and chloroquine (CQ) phosphate was found to be effective against 2019-nCoV infections. As the availability of remdesivir is less and the toxicity of chloroquine is high, both are not recommended though they are potential drugs. Chloroquine derivative hydroxychloroquine (HCQ) sulfate is found to be less toxic than its parent compound which is found to act effectively against novel coronavirus infection (Liu et al.2020).

All these medications are in lab trials or clinical trials so presently there are not many medications available for 2019-nCoV infections. Therefore, social distancing and effective hygienic practices are presently the most successful measures to limit the outbreak.

\section{Acknowledgements}

The author is deeply thankful to Dr. Githa Ann George for her advices and suggestions during the preparation of this report.

\section{References}

Corona Updates - Ministry of Health and Family Welfare, Government of India https://www.mohfw.gov.in/

Dhama, K.; Sharun, K.; Tiwari, R.; Sircar, S.; Bhat, S.; Malik, Y.S.; Singh, K.P.; Chaicumpa, W.; Bonilla-Aldana, D.K.; Rodriguez-Morales, A.J. Coronavirus Disease 2019 - COVID19. Preprints 2020, 2020030001 (doi: 10.20944/preprints202003.0001.v1). 
Drosten, C., Günther, S., Preiser, W., Van Der Werf, S., Brodt, H. R., Becker, S., ... \& Berger, A. (2003). Identification of a novel coronavirus in patients with severe acute respiratory syndrome. New England journal of medicine, 348(20), 1967-1976.

Fehr, A. R., \& Perlman, S. (2015). Coronaviruses: an overview of their replication and pathogenesis. In Coronaviruses (pp. 1-23). Humana Press, New York, NY.

Graham, R. L., Donaldson, E. F., \& Baric, R. S. (2013). A decade after SARS: strategies for controlling emerging coronaviruses. Nature Reviews Microbiology, 11(12), 836-848.

Kahn, J. S., \& McIntosh, K. (2005). History and recent advances in coronavirus discovery. The Pediatric infectious disease journal, 24(11), S223-S227.

Ksiazek, T. G., Erdman, D., Goldsmith, C. S., Zaki, S. R., Peret, T., Emery, S., ... \& Rollin, P. E. (2003). A novel coronavirus associated with severe acute respiratory syndrome. New England journal of medicine, 348(20), 1953-1966.

Liu, J., Cao, R., Xu, M., Wang, X., Zhang, H., Hu, H., ... \& Wang, M. (2020). Hydroxychloroquine, a less toxic derivative of chloroquine, is effective in inhibiting SARS-CoV-2 infection in vitro. Cell Discovery, 6(1), 1-4.

Malik, Y. S., Sircar, S., Bhat, S., Sharun, K., Dhama, K., Dadar, M., ... \& Chaicumpa, W. (2020). Emerging novel Coronavirus (2019-nCoV)-Current scenario, evolutionary perspective based on genome analysis and recent developments. Veterinary Quarterly, (just-accepted), 1-12.

Novel Coronavirus (2019-nCoV) situation reports - World Health Organization (WHO) https://www.who.int/emergencies/diseases/novel-coronavirus-2019/situation-reports/

Novel, C. P. E. R. E. (2020). The epidemiological characteristics of an outbreak of 2019 novel coronavirus diseases (COVID-19) in China. Zhonghua liu xing bing xue za zhi= Zhonghua liuxingbingxue zazhi, 41(2), 145.

Peiris, J. S. M., Lai, S. T., Poon, L. L. M., Guan, Y., Yam, L. Y. C., Lim, W., ... \& Cheng, V. C. C. (2003). Coronavirus as a possible cause of severe acute respiratory syndrome. The Lancet, 361(9366), 1319-1325.

Zaki, A. M., Van Boheemen, S., Bestebroer, T. M., Osterhaus, A. D., \& Fouchier, R. A. (2012). Isolation of a novel coronavirus from a man with pneumonia in Saudi Arabia. New England Journal of Medicine, 367(19), 1814-1820. 